\title{
The effects of short-term use of granulocyte colony-stimulating factor on bone metabolism in child cancer patients
}

\author{
(D) Ayse Bozkurt Turhan, ${ }^{1}$ () Cigdem Binay, ${ }^{2}$ (i) Ozcan Bor, ${ }^{3}$ (i) Enver Simsek ${ }^{2}$ \\ ${ }^{1}$ Division of Pediatric Hematology-Oncology, Department of Pediatrics, Goztepe Training and Research Hospital of Istanbul Medeniyet \\ University, Istanbul, Turkey \\ 2Division of Pediatric Endocrinology, Department of Pediatrics, Eskisehir Osmangazi University Faculty of Medicine, Eskisehir, Turkey \\ ${ }^{3}$ Division of Pediatric Hematology-Oncology, Department of Pediatrics, Eskisehir Osmangazi University Faculty of Medicine, Eskisehir, Turkey
}

\begin{abstract}
OBJECTIVE: The granulocyte colony-stimulating factor (G-CSF) is the most commonly used hematopoietic growth factor recombinant DNA technology. It affects bone metabolism by modulating both osteoclast and osteoblast functions. The aim of the present study was to investigate the effects of short-term use of G-CSF on bone metabolism in children with leukemia and solid tumors.
\end{abstract}

METHODS: Thirty-six patients with a malignancy who received G-CSF therapy according to chemotherapy protocols and another 20 growth factor-free cancer patients who were enrolled as controls were included in the study. The serum osteocalcin and urinary free deoxypyridinoline levels were measured before the start of G-CSF therapy, on day 3 after treatment, and 7 days after G-CSF therapy was discontinued. In the control group, the measurements were made during corticosteroid and methotrexate-free chemotherapy.

RESULTS: The mean osteocalcin level $(8.6 \pm 2.3 \mathrm{ng} / \mathrm{mL})$ from before the onset of treatment decreased significantly $(7.7 \pm 2.3$ $\mathrm{ng} / \mathrm{mL})$ on day 3 of G-CSF therapy and significantly increased after 7 days of G-CSF therapy $(7.9 \pm 2.2 \mathrm{ng} / \mathrm{mL})(p<0.001$ and $p<0.001$, respectively), which was still significantly lower than the pre-G-CSF values $(p<0.001)$. The urinary free deoxypyridinoline level significantly increased on day 3 of G-CSF treatment $(25.6 \pm 6.5 \mathrm{nmol} / \mathrm{mmol} \mathrm{Cr})$ and significantly decreased after 7 days of G-CSF therapy $(22.6 \pm 6.4 \mathrm{nmol} / \mathrm{mmol} \mathrm{Cr})(p<0.001$ and $p<0.001$, respectively), which was still significantly higher than the values recorded before G-CSF therapy $(p<0.001)$.

CONCLUSION: The findings show that the short-term use of G-CSF in children with cancer can affect bone metabolism and can play a role in metabolic changes. Decreased osteoblastic activity and increased osteoclastic activity suggest that osteoporosis may be associated with bone pain in these patients.

Keywords: Bone; cancer; granulocyte colony-stimulating factor; hematopoietic growth factor.

Cite this article as: Bozkurt Turhan A, Binay C, Bor O, Simsek E. The effects of short-term use of granulocyte colony-stimulating factor on bone metabolism in child cancer patients. North Clin Istanb 2018;5(4):277-281.

$\mathrm{H}^{2}$ ematopoietic growth factors are glycoprotein hormones that regulate the proliferation and differentiation of mature blood and hematopoietic progenitor cells. The granulocyte colony-stimulating factor (G-CSF) prepared by recombinant DNA technology is the most commonly used hematopoietic growth factor. G-CSF regulates the survival, proliferation, and differentiation of neutrophils and activates and stimulates the functions of mature neutrophils. It decreases the neutropenic period following intensive chemotherapy in children with

Received: Kasım 08, 2017 Accepted: Aralık 08, 2017 Online: December 03, 2018

Correspondence: Dr. Ayse BOZKURT TURHAN. Medeniyet Universitesi, Goztepe Egitim ve Arastirma Hastanesi,

Cocuk Hematoloji Klinigi, Istanbul, Turkey.

Tel: +90 5327247180 e-mail: aysebturhan@hotmail.com

(c) Copyright 2018 by Istanbul Provincial Directorate of Health - Available online at www.northclinist.com 
acute leukemia and solid tumors and also decreases the frequency of infections and deaths due to infections [1].

Although G-CSF can be used intravenously and subcutaneously, subcutaneous use is preferred because it is less toxic and more effective [1]. The side effects of shortterm use of G-CSF are usually mild fever, fatigue, nausea, and bone pain. The most prevalent side effect is mild to moderate bone pain [2-3].

G-CSF affects bone metabolism by modulating both osteoclast and osteoblast functions. Bone morphogenetic protein 2 , an effective inhibitor of the cartilage and bone, is also an effective regulator in the conduction pathway [4]. Bone metabolism is a continuous and dynamic process characterized with new bone formation by osteoblasts and bone resorption by osteoclasts [5]. Biochemical markers of bone production metabolism include serum alkaline phosphatase (ALP), serum osteocalcin, and serum procollagen type 1 peptides. Biochemical markers of bone resorption metabolism are urinary calcium, hydroxyproline, Ntelopeptide, C-telopeptide, pyridinoline, and deoxypyridinoline. Serum osteocalcin levels are indicative of osteoblastic activity reflecting bone mineralization rate. The level of urine deoxypyridinoline is considered to be a sensitive and specific indicator of osteoclastic activity [6-9].

Long-term treatment with G-CSF is characterized by clinically significant osteopenia, decreased bone mineral density, and compression fractures in the vertebra [10, $11]$. The prevalence of osteopenia has been reported as $28 \%$ in children under chronic G-CSF treatment due to severe congenital neutropenia [10]. Not only long-term use but also short-term G-CSF treatment may affect bone metabolism. While long-term G-CSF treatment resulted in increased osteoclastogenesis, new evidence reveals that short-term administration of G-CSF reduces the number and activity of osteoblast [12-14].

It has been observed that the level of osteocalcin, which is one of the markers of bone formation, was significantly lower than baseline, whereas bone and bonespecific ALP levels significantly increased. It has been suggested that bone pain observed in patients receiving G-CSF may be due to the effect of osteoblastic activity, whereas short-term (3-7 days) G-CSF administration does not directly stimulate osteoclasts, and osteoporosis may occur indirectly via the activation of osteoclasts as a result of the stimulation of osteoblasts [2].

In healthy progenitor cells and stem cell donors, it has been observed that short-term (3-7 days) G-CSF treatment temporarily suppressed osteoblastic activity and increased osteoclastic activity $[2,12]$.

We aimed to investigate the effects of short-term GCSF use on bone metabolism in children with leukemia and solid tumors because of the small number of studies investigating the effects of short-term G-CSF treatment on bone metabolism.

\section{MATERIALS AND METHODS}

Fifty-six patients with hematological malignancies and solid tumors followed up by the Department of Pediatric Hematology-Oncology, Faculty of Medicine University of Eskisehir Osmangazi, including 36 patients receiving G-CSF therapy and 20 controls not receiving growth factor in compliance with chemotherapy protocols, were included in the study. Approval was obtained from the local ethics committee of the university where the present study was conducted.

None of the solid tumor groups had bone involvement, and baseline calcium phosphorus and ALP values were within normal limits. Age, gender, diagnosis of primary disease, follow-up period, chemotherapy period, last chemotherapeutic drug received, development of neutropenia, and duration of G-CSF treatment were recorded. Among biochemical analyses, calcium, phosphorus, and ALP levels were analyzed for the estimation of bone metabolism.

Serum osteocalcin and urine free deoxypyridinoline levels of the patients in the study group were measured before the beginning of G-CSF treatment, 3 days after onset of G-CSF therapy, and 7 days after discontinuation of G-CSF treatment. Serum osteocalcin and urine levels were measured in the control group during chemotherapy without corticosteroids and methotrexate that could affect bone metabolism. In the treated group, G-CSF chemotherapy protocol was started on day 3 after treatment and administered subcutaneously every morning at a dose of $5 \mu \mathrm{g} / \mathrm{kg}$ daily. Every morning, fasting blood samples were placed in heparinized tubes for the measurement of serum osteocalcin, and $10 \mathrm{~cm}^{3}$ urine samples were collected for the measurement of deoxypyridinoline and urine creatinine. Patients with abnormal parathormone or vitamin $\mathrm{D}$ levels who did not provide consent were excluded from the study.

Data were analyzed by SPSS Windows 18 (SPSS Inc., Chicago, IL, USA). For descriptive statistical analysis, values were expressed as mean \pm standard deviation (minimum-maximum) using the one-way analysis of 
TABLE 1. Demographic characteristics of the patients

\begin{tabular}{|c|c|c|c|c|}
\hline \multirow[t]{2}{*}{ Characteristics } & \multicolumn{2}{|c|}{$\begin{array}{l}\text { Patient } \\
\text { group } \\
(n=36)\end{array}$} & \multicolumn{2}{|c|}{$\begin{array}{l}\text { Control } \\
\text { group } \\
(n=20)\end{array}$} \\
\hline & $\mathrm{n}$ & $\%$ & $\mathrm{n}$ & $\%$ \\
\hline Age (years), median (min.-max.) & \multicolumn{2}{|c|}{$8.5(1-17)$} & \multicolumn{2}{|c|}{$7(2.1-15)$} \\
\hline Gender (male) & 44.4 & 16 & 50 & 10 \\
\hline \multicolumn{5}{|l|}{ Diagnosis } \\
\hline Acute lymphoblastic leukemia & 50.0 & 18 & 50.0 & 10 \\
\hline Lymphoma & 30.6 & 11 & 20.0 & 4 \\
\hline Acute myeloblastic leukemia & 0 & 0 & 15.0 & 3 \\
\hline Solid tumors & 19.4 & 7 & 15.0 & 3 \\
\hline
\end{tabular}

Min.: Minimum; Max.: Maximum.

variance for variables with normal distribution and median $(25 \%-75 \%)$ for non-normally distributed variables, and the results were compared using the Mann-Whitney U test. Chi-square test or Fisher's exact test was used for comparison of categorical data, and Student's t-test was used for comparison of continuous data. A $p$ value $<0.05$ was accepted as significant.

\section{RESULTS}

Fifty-six patients with G-CSF treatment and 20 controls without growth factor were included in the study. The me- dian ages of the patients and the control subjects were 8.5 (1-17) and 7 (2.1-15) years, respectively, with no statistically significant intergroup difference $(p=0.24)$. The male gender ratios were $44.4 \%(n=16)$ in the patient group and $50 \%(n=10)$ in the control group with no statistically significant difference between the groups $(p=0.69)$.

The patients included in the study were followed up with the diagnoses of lymphoblastic leukemia (ALL) $(\mathrm{n}=18,50 \%)$, lymphoma (including 11 (30.6\%) patients with non-Hodgkin lymphoma), and solid tumors $(\mathrm{n}=7,19.4 \%$; including patients with neuroblastoma $(n=3)$, Ewing's sarcoma $(n=2)$, Wilms tumor $(n=1)$, and primitive neuroectodermal tumor (PNET) $(n=1)$ ) in the patient group, whereas the patients in the control group $(n=20)$ were followed up with the diagnoses of acute ALL $(n=10,50 \%)$, acute myeloblastic leukemia $(n=3,15 \%)$, lymphoma $(n=4,20 \%$; including 1 patient with non-Hodgkin lymphoma $(\mathrm{n}=1))$, and solid tumors $(n=3,15 \%$; including neuroblastoma $(n=1)$, Wilms tumor $(n=1)$, and PNET $(n=1))$. The median duration of G-CSF administration was 6.4 (3-11) days in the patient group. Table 1 shows the demographic data of the patient and control groups.

When the average serum osteocalcin, serum ALP, and urine deoxypyridinoline levels were compared, there was no statistically significant difference between the pretreatment values of the G-CSF group and the levels of the control group (Table 2). Similarly, serum calcium, phosphorus, ALP, and vitamin D levels were not different between the groups.

TABLE2. Comparison of serum osteocalcin, alkaline phosphatase, and urine deoxypyridinoline levels

\begin{tabular}{|c|c|c|c|c|}
\hline & \multirow[t]{2}{*}{ Control group $(n=20)$} & \multicolumn{3}{|c|}{ G-CSF group $(n=36)$} \\
\hline & & Pretreatment & $\begin{array}{c}3 \text { days of } \\
\text { treatment* }\end{array}$ & $\begin{array}{l}7 \text { days after } \\
\text { treatment }{ }^{£, \nsucc}\end{array}$ \\
\hline Serum osteocalcin level (ng/ml) & $8.6 \pm 1.8$ & $8.6 \pm 2.3$ & $7.7 \pm 2.3$ & $7.9 \pm 2.2$ \\
\hline Mean $\pm S D$ (min.-max.) & $(5.4-11.7)^{€}$ & $(5.2-13.4)$ & $(4.1-12.8)$ & $(4.3-12.9)$ \\
\hline Mean $\pm S D$ (min.-max.) & $(9.0-30.6)^{€}$ & $(9.3-30.6)$ & $(14.0-36.6)^{*}$ & $(11.0-37.6)^{£, 4}$ \\
\hline Serum alkaline phosphatase level (U/I) & $152 \pm 38$ & $139 \pm 47$ & $145 \pm 50$ & $161 \pm 53$ \\
\hline Mean $\pm S D(\min .-\max )$. & $(93-222)^{€}$ & $(56-250)$ & $(56-261)$ & $(58-313)^{a, \beta}$ \\
\hline
\end{tabular}

G-CSF: Granulocyte colony-stimulating factor; Max.: Maximum; Min.: Minimum; SD: Standard deviation; $\epsilon^{\mathfrak{N}}$ o difference when compared with pretreatment levels in the G-CSF group; *A significant difference when compared with pretreatment levels $(p<0.001)$. ${ }^{\ddagger} A$ significant difference when compared with 3 -day levels $(p<0.001)$; ${ }^{¥} \mathrm{~A}$ significant difference when compared with pretreatment levels $(p<0.001) ;{ }^{A} \mathrm{~A}$ significant difference when compared with 3 -day levels $(p=0.001) ;{ }^{\beta} A$ significant difference when compared with pretreatment levels $(p=0.001)$. 
The mean osteocalcin level before onset of treatment $(8.6 \pm 2.3 \mathrm{ng} / \mathrm{ml})$ significantly decreased on day 3 of G-CSF treatment $(7.7 \pm 2.3 \mathrm{ng} / \mathrm{ml})$ and significantly increased 7 days after discontinuation of G-CSF therapy $(7.9 \pm 2.2 \mathrm{ng} / \mathrm{ml})(\mathrm{p}<0.001$ and $\mathrm{p}<0.001$, respectively). However, they were still found to be significantly lower than the values before G-CSF treatment $(\mathrm{p}<0.001$, Table 2$)$.

When we compared the mean urine free deoxypyridinoline levels on days 0,3 , and 7 after drug withdrawal, free urinary deoxypyridinoline level $(19.9 \pm 5.9 \mathrm{nmol} / \mathrm{mmol}$ $\mathrm{Cr}$ ) significantly increased on day 3 of G-CSF treatment $(25.6 \pm 6.5 \mathrm{nmol} / \mathrm{mmol} \mathrm{Cr})$ and significantly decreased 7 days after discontinuation of G-CSF $(22.6 \pm 6.4 \mathrm{nmol} /$ mmol Cr) $(p<0.001$ and $p<0.001$, respectively). However, it was still significantly higher than the values before the onset of G-CSF treatment $(\mathrm{p}<0.001)$ (Table 2$)$.

Serum ALP levels were significantly higher $(145 \pm 50$ $\mathrm{U} / \mathrm{l})$ on day 3 of G-CSF treatment $(\mathrm{p}<0.001$ and $p<0.001$, respectively) than values before onset of treatment $(139 \pm 47 \mathrm{U} / \mathrm{l})$. While it remained at significantly higher levels at 7 days after discontinuation of G-CSF treatment $(161 \pm 53 \mathrm{U} / \mathrm{l})(\mathrm{p}=0.001)$.

\section{DISCUSSION}

In the present study, it was found that the effects of short-term G-CSF treatment on bone metabolism in patients with pediatric cancer significantly changed the levels of biochemical markers related to bone formation and resorption.

Osteoblasts provide regeneration of the bone tissue by proliferation, differentiation, and mineralization of the extracellular matrix. Osteocalcin is the major noncollagenous protein of the bone and is produced by osteoblasts during bone formation and binds to hydroxyapatite in the newly mineralized bone. Takamatsu et al. [12] reported that osteocalcin levels are significantly reduced on day 3 of G-CSF treatment and returned to baseline levels shortly after treatment.

Serum ALP levels are associated with bone matrix formation and osteoblastic activity. ALP is produced by immature osteoblasts, and osteocalcin is produced by more mature osteoblasts [15]. It has been thought that the increase in ALP level and decrease in serum osteocalcin level after G-CSF treatment may be due to the downregulation of mature osteoblast and osteocalcin expressions [2]. Similarly, in our study, it was found that serum ALP levels increased, and osteocalcin levels decreased; these changes continued after termination of treatment in relation to G-CSF treatment. This condition has been associated with a decrease in osteoblastic activity, an increase in osteoblast turnover, an increase in osteoblast apoptosis, and a decrease in differentiation to mature osteoblasts after G-CSF treatment [16]. Cristopher et al. [16] reported that G-CSF treatment reduces the number of mature osteoblasts by increasing apoptosis and the number of osteoprogenitor cells in the bone marrow. Rapid recovery of osteoblastic activity after discontinuation of therapy is thought to occur due to the accumulation of these osteoblast precursors.

As a result of long-term use of G-CSF treatment, it has been reported that significant degrees of osteopenia and osteoporosis developed, and bone mineral density values significantly decreased due to an increase in osteoclastic activity that may cause vertebral fractures $[10$, 17]. It has been detected that increased monocytic precursors with G-CSF treatment were the source of osteoclasts, and also osteoclast formation and activity increased with other direct or indirect mechanisms $[10,18$, 19]. Dale et al. [10] proposed a reduction in the level of osteoprotegerin $(\mathrm{OPG})$ regulated by osteoblasts in relation to increased osteoclastic activity, mechanisms such as disruption of the OPG/receptor activator of nuclear factor kappa-B ligand ratio.

In the bone, collagen fibrils are cross-linked with deoxypyridinoline, such as dipyrimidine [20]. Deoxypyridinoline, especially in the bone and dentin, is released from bone collagen during bone resorption and excreted in urine without further deterioration. Therefore, the concentration of deoxypyridinoline in urine can be used as a specific symptom of bone resorption. Takamatsu et al. [12] showed that serum osteocalcin levels decrease, and urine deoxypyridinoline levels increase with 6 days of GCSF $(10 \mu \mathrm{g} / \mathrm{kg})$ treatment in patients with breast cancer. It has been observed that an increase in osteoclastic activity peaked at 7 days of treatment and coursed at high levels until at least 1 week after discontinuation of treatment. While with pamidronate treatment, an increased level of urine dihydropyridine was associated with GCSF treatment [12].

Although the G-CSF dose was lower in our study (5 $\mu \mathrm{g} / \mathrm{kg}$ ), we obtained similar results for osteoclastic activity.

The findings of our study are similar to previous studies showing that prolonged administration of G-CSF in congenital neutropenia may stimulate osteoclast-medi- 
ated bone resorption [21, 22]. Similarly, significant expansion in bone space and a reduction in bone mass have been shown in transgenic mice with chronic and excessive G-CSF expressions [23]. These studies suggest that there may be a relationship between bone remodeling and mobilization of progenitor cells.

Children are different from adults in terms of bone metabolism, and this difference may contribute to the variability of results. Although there are few studies on the effects of short-term G-CSF use on bone metabolism in the pediatric patient group [17], our study is one of the studies performed in children with cancer.

In conclusion, our results showed that the use of short-term G-CSF in children with cancer may affect bone metabolism and may play a role in metabolic changes. A decrease in osteoblastic activity and an increase in osteoclastic activity suggest that osteoporosis in these patients may be associated with bone pain by contributing to osteoporosis in these patients. These findings should be warning signs for closer follow-up of the patients, and further studies should be performed with greater number of patients.

Conflict of Interest: The authors declare that they have not received any financial or any other support that might lead to any conflict of interest.

Authorship Contributions: Concept - A.B.T., C.B., O.B., E.S.; Design - A.B.T., C.B., O.B., E.S.; Supervision - A.B.T.; Materials - A.B.T., C.B.; Data collection \&/or processing - A.B.T., C.B.; Analysis and/or interpretation - A.B.T., O.B., E.S.; Writing - A.B.T., C.B., O.B., E.S.; Critical review - A.B.T.

\section{REFERENCES}

1. Lehrnbecher T, Welte K. Haematopoietic growth factors in children with neutropenia. Br J Haematol 2002;116:28-56. [CrossRef]

2. Froberg MK, Garg UC, Stroncek DF, Geis M, McCullough J, Brown DM. Changes in serum osteocalcin and bone-specific alkaline phosphatase are associated with bone pain in donors receiving granulocytecolony-stimulating factor for peripheral blood stem and progenitor cell collection. Transfusion 1999;39:410-4. [CrossRef]

3. Steward WP. Granulocyte and granulocyte-macrophage colony-stimulating factors. Lancet 1993;342:153-7. [CrossRef]

4. Kuwabara H, Wada T, Oda T, Yoshikawa H, Sawada N, Kokai Y, et al. Overexpression of the granulocyte colony-stimulating factor gene impairs bone morphogenetic protein responsiveness in mice. Lab Invest 2001;81:1133-41. [CrossRef]

5. Christenson RH. Biochemical markers of bone metabolism: an overview. Clin Biochem 1997;30:573-93. [CrossRef]

6. Eastell R, Robins SP, Colwell T, Assiri AM, Riggs BL, Russell RG. Evaluation of bone turnover in type I osteoporosis using biochemical markers specific for both bone formation and bone resorption. Osteo- poros Int 1993;3:255-60. [CrossRef]

7. Husain SM, Mughal Z, Williams G, Ward K, Smith CS, Dutton J, et al. Urinary excretion of pyridinium crosslinks in healthy 4-10 year olds. Arch Dis Child 1999;80:370-3. [CrossRef]

8. Risteli L, Risteli J. Biochemical markers of bone metabolism. Ann Med 1993;25:385-93. [CrossRef]

9. Romberg RW, Werness PG, Riggs BL, Mann KG. Inhibition of hydroxyapatite crystal growth by bone-specific and other calcium-binding proteins. Biochemistry 1986;25:1176-80. [CrossRef]

10. Dale DC, Cottle TE, Fier CJ, Bolyard AA, Bonilla MA, Boxer LA, et al. Severe chronic neutropenia: treatment and follow-up of patients in the Severe Chronic Neutropenia International Registry. Am J Hematol 2003;72:82-93. [CrossRef]

11. Lee MY, Fukunaga R, Lee TJ, Lottsfeldt JL, Nagata S. Bone modulation in sustained hematopoietic stimulation in mice. Blood 1991;77:213541.

12. Takamatsu Y, Simmons PJ, Moore RJ, Morris HA, To LB, Lévesque JP. Osteoclast-mediated bone resorption is stimulated during short-term administration of granulocyte colony-stimulating factor but is not responsible for hematopoietic progenitor cell mobilization. Blood 1998;92:3465-73.

13. Katayama Y, Battista M, Kao WM, Hidalgo A, Peired AJ, Thomas SA, et al. Signals from the sympathetic nervous system regulate hematopoietic stem cell egress from bone marrow. Cell 2006;124:407-21.

14. Semerad CL, Christopher MJ, Liu F, Short B, Simmons PJ, Winkler I, et al. G-CSF potently inhibits osteoblast activity and CXCL12 mRNA expression in the bone marrow. Blood 2005;106:3020-7. [CrossRef]

15. Delmas PD. Biochemical markers of bone turnover. J Bone Miner Res 1993;8 Suppl 2:S549-55. [CrossRef]

16. Christopher MJ, Link DC. Granulocyte colony-stimulating factor induces osteoblast apoptosis and inhibits osteoblast differentiation. J Bone Miner Res 2008;23:1765-74. [CrossRef]

17. Watanabe T, Suzuya H, Onishi T, Kanai S, Kaneko M, Watanabe H, et al. Effect of granulocyte colony-stimulating factor on bone metabolism during peripheral blood stem cell mobilization. Int J Hematol 2003;77:75-81. [CrossRef]

18. Li S, Li T, Chen Y, Nie Y, Li C, Liu L, et al. Granulocyte Colony-Stimulating Factor Induces Osteoblast Inhibition by B Lymphocytes and Osteoclast Activation by T Lymphocytes during Hematopoietic Stem/Progenitor Cell Mobilization. Biol Blood Marrow Transplant 2015;21:1384-91. [CrossRef]

19. Purton LE, Lee MY, Torok-Storb B. Normal human peripheral blood mononuclear cells mobilized with granulocyte colony-stimulating factor have increased osteoclastogenic potential compared to nonmobilized blood. Blood 1996;87:1802-8.

20. Morris HA, Chatterton BE, Ross PD, Durbridge TC. Diagnostic procedures. Metabolic Bone and Stone Disease. In: Need AG, Morris HA, editors. Metabolic Bone and Stone Disease. ${ }^{\text {rd }}$. Edinburgh: Churchill Livingstone; 1993, p. 339-79.

21. Bonilla MA, Dale D, Zeidler C, Last L, Reiter A, Ruggeiro M, et al. Long-term safety of treatment with recombinant human granulocyte colony-stimulating factor ( $\mathrm{r}$-metHuG-CSF) in patients with severe congenital neutropenias. Br J Haematol 1994;88:723-30. [CrossRef]

22. Bishop NJ, Williams DM, Compston JC, Stirling DM, Prentice A. Osteoporosis in severe congenital neutropenia treated with granulocyte colony-stimulating factor. Br J Haematol 1995;89:927-8. [CrossRef]

23. Takahashi T, Wada T, Mori M, Kokai Y, Ishii S. Overexpression of the granulocyte colony-stimulating factor gene leads to osteoporosis in mice. Lab Invest 1996;74:827-34. 